\title{
Pure agraphia and unilateral optic ataxia associated with a left superior parietal lobule lesion
}

\author{
S H A UER B ACH A N D M P A LEX A NDER \\ From the Neurobehavioral Unit, Department of Neurology, Boston Veterans Administration \\ Medical Center and Boston University School of Medicine
}

SUMMARY Impairment in visually guided reaching and pure agraphia are described in a patient with a left superior parietal embolic infarction. Identification of these disorders required specific but simple test procedures. Both disorders may reflect disruption of specific integrative functions of the superior parietal lobule.

Unilateral impairment of visually guided hand movements (optic ataxia) and pure agraphia have each been described in association with posterior parietal lobe lesions. Optic ataxia probably results from a lesion in pathways projecting anteriorly from the visual association areas to pre-motor centres. ${ }^{1}$ Pure agraphia has been described with frontal lobe, posterior parietal lobe and other more diffuse brain lesions (reviewed by Hécaen and Marie $^{2}$; Hécaen and Albert ${ }^{3}$ ). We describe a patient with both unilateral optic ataxia and pure agraphia who had a discrete left posterior parietal lobe lesion. The association of these disorders with such a small lesion suggests that they may share a common mechanism.

\section{Case report}

The patient is a 56-year-old, right-handed mail-carrier with an eighth grade education. The patient was in his usual state of health until several days prior to admission when he began to have difficulty sorting his mail. He usually did this by placing the letters into their appropriate slots with his right hand according to the name on the address label. He was able to read the name, but was not able to place the letters reliably into the correct slot. His sorting errors went to both sides of the correct slot. He was aware of his errors and made attempts to correct them. He also

Address for reprint requests: Dr MP Alexander, Neurobehavioral Unit, Boston VA Medical Center, 150 South Huntington Avenue. Boston, Mass 02130 USA.

Accepted 21 January 1981 noted difficulty inserting his car key into the ignition, difficulties manipulating food on to his fork, and difficulty directing his hand and fork precisely. All of these problems occurred with his right hand only. He had no weakness, and he experienced no clumsiness when using his right hand in non-visually related tasks such as buttoning his clothes. Over the next few days he experienced problems writing, particularly in signing his name. He tended to swerve when driving and had difficulty parallel-parking, but he could not identify a specific cause. He was admitted to the Neurology service to evaluate these complaints.

On admission, general medical examination showed no abnormality. Speech, auditory comprehension and repetition were normal. He could follow a 4-step pointing sequence. Reading aloud and for comprehension was intact. He had great difficulty with writing and copying. Right-left orientation, finger naming, and calculations were normal. Cranial nerve examination was normal, including intact visual fields to confrontation. There was a mild upward drift of his outstretched right upper extremity with some pronation; tone co-ordination and strength otherwise were normal. Rapid alternating movements performed under visual guidance with his right hand were poor. Deep tendon reflexes were bilaterally symmetrical with flexor plantar reflexes. Sensory examination was normal for pinprick, temperature and vibration. $\mathrm{He}$ had minimal difficulties with position sense testing in the right hand; on double simultaneous tactile testing he occasionally mislocalised on the right hand. An electroencephalogram was normal. A computed tomogram showed a small enhancing infarct in the left superior parietal lobule, corresponding to Brodman's area 7 (fig 1). Carotid arteriography showed a distal branch occlusion of the left posterior parietal artery. 

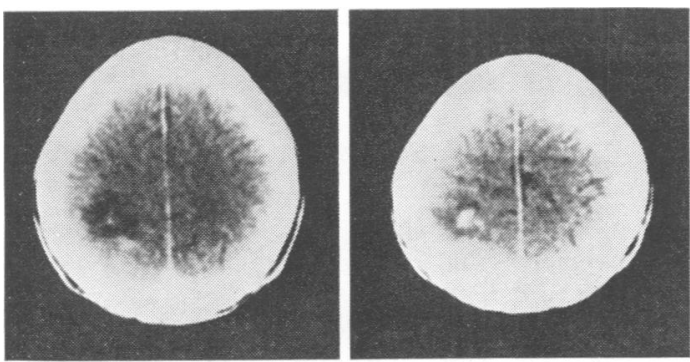

Fig 1 Contrast enhanced computerised tomographic scan showing discrete enhancing lesion in left superior parietal lobule.

When re-examined two weeks later he reported considerable improvement in his co-ordination although his writing difficulties persisted. Motor and sensory examination showed no abnormality, but the patient had developed a marked preference for his left hand for common daily activities (holding a cup of coffee, pointing to objects, etc). Two weeks after admission, he was alert and oriented. Digit span was seven forward, three reverse. Spontaneous speech, auditory comprehension and repetition were intact. Reading aloud and for comprehension were normal. He could perform simple calculations. With more complex problems he had difficulty, became frustrated and refused to complete the problems. Right-left orientation, body part identification and praxis testing were normal. Copying of figures was sloppy, but he preserved the general configuration and many of the details. The Albert line-crossing test for neglect ${ }^{4}$ was normal. More detailed tests of writing and hand use were performed.

Writing (fig $2 \mathrm{a}$ and $\mathrm{b}$ ) The patient's handwriting was untidy and poorly formed. He made frequent errors in spelling with letter omissions, substitutions and repetition. The patient would cross lines or make loops in inappropriate places. Occasionally he would omit an entire word. When asked to spell orally these same words, he could usually do so correctly. Using the word list from the Wide Range Achievement Test he performed at a 6.6 grade level with oral spelling and below a fourth grade level with written spelling. $\mathrm{He}$ was able to spell correctly aloud many words that he coud not write correctly. These errors were present for spontaneous writing as well as for writing to dictation and to copy. They were present in cursive and printed productions. The patient refused further testing and left-handed writing samples were not obtained.

Tests of visually guided reaching His initial complaints suggested a disorder in visually-guided reaching. To pursue this, we administered a version of a test described by Holmes, ${ }^{5}$ and modified by Levine, Kaufman and Mohr. ${ }^{6}$ The patient was asked to fixate on the nose of the examiner. He was then asked to touch quickly the eraser tip of a pencil held somewhere in front of him. He used the index finger of a designated hand. Each hand was used individually, pointing into both the right and left hemi-fields. There were no errors pointing into the left hemi-field with his left hand. There was some difficulty accurately reaching with either hand into its contralateral hemifield. By comparison, reaching with his right hand into the right hemi-field was greatly impaired. When the task was repeated without fixation of gaze, the patient had no difficulty accurately touching the targets.

\section{Discussion}

Our patient presented with two prominent problems: agraphia without other language disturbances and an impairment in visually-guided hand
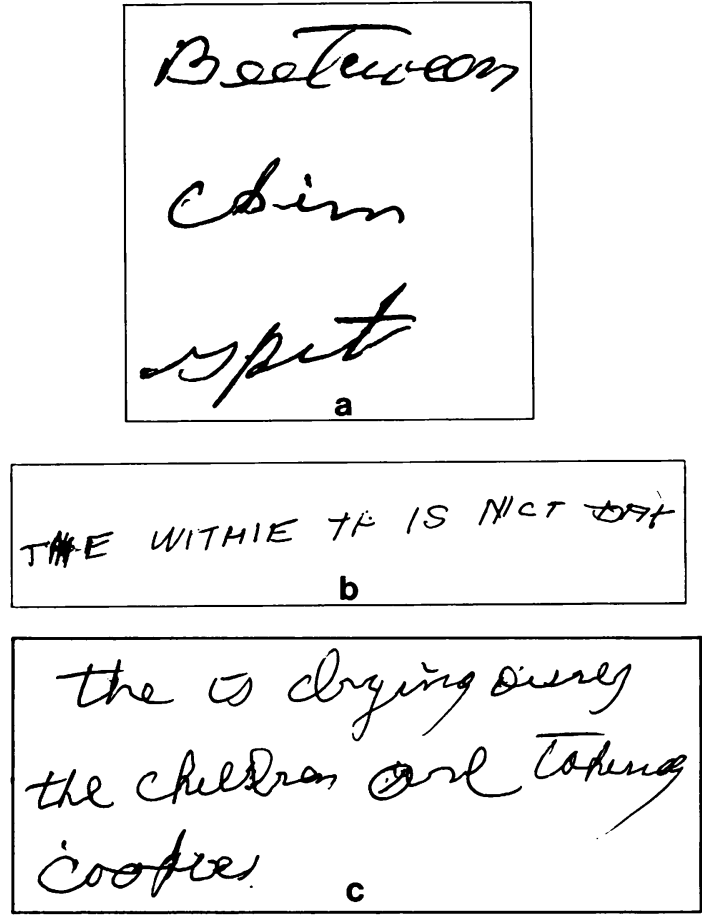

Fig 2 Samples of handwriting, showing the errors described in the test. (a) Handwriting to dictation taken from the Wide Range Achievement Test. Here the patient intended to write the words BETWEEN, CHIN, SPLIT and was able to do it correctly orally. (b) Spontaneous handwriting in response to a command to write about the weather. The patient intended to write: THE WEATHER IS NICE TODAY. He was able to spell orally all the words correctly.

(c) Handwriting when asked to describe the Cookie Theft Picture. ${ }^{16}$ The patient intended to write: THE MOTHER IS DRYING DISHES, THE CHILDREN ARE TAKING COOKIES. Again, he made no errors in the oral production of these sentences. 
movements (optic ataxia). The agraphia was initially considered a non-specific concomitant of a clumsy hand, but further testing delineated its specific nature. The optic ataxia was unusually important because of his job as a mail sorter, but its specific characterisation as impaired visually guided reaching became manifest only with special testing. ${ }^{6}$ Both of these disorders might easily be overlooked.

Pure agraphia is an infrequent result of focal brain lesions, but the few reported cases have involved one or two specific areas: a small region in the left posterior frontal lobe 78 or a small region in the left superior parietal lobe..$^{9-11}$ Our patient's lesion was in the latter area. Patients with pure agraphia from superior parietal lobule lesions have had the same complex writing impairment as our patients including misspellings, letter and word omissions, additions and repetitions, and most compellingly, oral spelling superior to written spelling. These cases may be uncommon because isolated superior parietal lesions are rare. When caused by infarction, simultaneous involvement of the inferior parietal lobule will produce additional language disturbance. ${ }^{12}$

Impairment of hand movements under visual guidance has been reviewed by Levine, Kaufman and Mohr, ${ }^{6}$ and by Damasio and Benton. ${ }^{1}$ Both reports summarise the anatomical and electrophysiological data which support the importance of the posterior superior parietal lobe (areas 5 and 7) in the control of visually-guided movements in the contralateral field. Its importance is twofold. Firstly, this portion of the superior parietal lobe has the structural capacity for cross-modal sensory integrations. ${ }^{13}$ Secondly, it immediately overlies the white matter pathways which connect visual association cortex (area 19) and motor association cortex (area 6) ${ }^{14}$ Both the impaired supramodal spatial integration and the disconnection of parietal and frontal association cortices are relevant to the functional disorder in visually guided reaching.

Chedru and Geschwind ${ }^{15}$ argued that all cases of pure agraphia are, in fact, not pure, but that the agraphia is secondary to some other more basic deficit, commonly motor impairment or confusion. We believe that pure agraphia in our case may be partly produced by a general difficulty in visually guided hand movements and that small lesions in the posterior superior dominant parietal lobe may result in disordered written language independent of other language disturbances.

\section{References}

1 Damasio AR, Benton AL. Impairment of hand movement under visual guidance. Neurology (Minneap) 1979; 29:170-8.

2 Marie P, Hécaen H. Agraphia: writing disorders associated with unilateral cortical lesions. In: Heilman KM, Valenstein E, eds. Clinical Neuropsychology, New York: Oxford University Press, 1979.

3 Hécaen H, Albert M. Human Neuropsychology. New York: John Wiley and Sons, 1978; 59-66.

4 Albert M. A simple test of visual neglect. Neurology (Minneap) 1973; 23:638-64.

5 Holmes G. Disturbances of visual orientation. Br J Ophthalmol 1918; 2:449-68, 506-16.

6 Levine D, Kaufman KJ, Mohr JP. Inaccurate reaching associated with a superior parietal lobe tumor. Neurology (Minneap) 1978; 25:556-61.

7 Pennfield W, Roberts L. Speech and Brain Mechanisms, Princeton: Princeton University Press, 1959.

8 Dubois J, Hécaen H, Marie P. L'agraphie pure. Neuropsychologia 1969; 7:271-86.

9 Russell R, Espir MLE. Traumatic Aphasia, Oxford: Oxford University Press, 1961.

10 Kinsbourne M, Rosenfield DB. Agraphia selective for written spelling: an experimental case study. Brain Lang 1974; 1:215-26.

11 Rosait G, DeBastiani P. Pure agraphia: a discrete form of aphasia. J Neurol Neurosurg Psychiatry 1979; 42:266-9.

12 Hier DB, Mogil SI, Rubin NP, Komros GR. Semantic aphasia: a neglected entity. Brain Lang $1980 ; 10(1): 120-31$.

13 Montcastle VB, Lynch JC, Georgepoulos A. Posterior parietal association cortex of the monkey: command functions for operations within extra-personal space. J Neurophysiol 1975; 38: 871-908.

14 Haxima R, Kuypers HCJM. Intrahemispheric cortical connexions and visual guidance of hand and finger movements in the rhesus monkey. Brain 1975; 98:239-60.

15 Chedru F, Gaschwind N. Writing disturbances in acute confusional state. Neuropsychologia 1972; 10:343-53.

16 Goodglass H, Kaplan E. The Assessment of Aphasia and Related Disorders. Philadelphia, Lea and Febiger, 1972. 